\title{
A Windmills OF YouR Mind: METACOGNITION AND LIFELONG LEARNING
}

\author{
Greg J. Evans \\ Institute for Studies in Transdisciplinary Engineering Education and Practice (ISTEP), \\ Faculty of Applied Science and Engineering, University of Toronto \\ greg.evans@utoronto.ca
}

\begin{abstract}
Lifelong learning is becoming increasingly important to career success as an engineer. This paper advocates for the explicit instruction of metacognition as a mechanism to support self-directed and lifelong learning. Relevant literature is synthesised with an emphasise on how this teaching might be operationalised. Experience gained through preliminary inclusion of metacognition in a core second year course is described. It appears that easy ways exist to integrate instruction of metacognition into existing undergraduate engineering courses that should potentially yield major benefits to students.
\end{abstract}

Keywords: Metacognition, lifelong learning, self-directed learners.

\section{INTRODUCTION}

The accelerating pace of technological innovation is making lifelong learning increasingly important as a competency for career success [1]. As we move from a knowledge-based society into a global learning-based society, success will become less about what our graduates know and more about how easily they can identify, retrieve, process, and apply new knowledge [2]. Our role as educators should, in turn, shift away from serving up content, to helping students "learn how to learn" as a primary outcome [3]. Essentially, the knowledge-base constructed at university should shift from an end in and of itself to the end of a beginning, whose primary purpose is to enable and support future learning; more simply, the content "is actually the vehicle for skill development" [4].

In this paper, I advocate for proactive instruction of metacognition to enable lifelong learning. The paper emerged from discussions at a $3 \mathrm{M}$ National Teaching Fellows retreat that I was fortunate to attend in Fall 2017. The paper was motivated by my realisation that knowing how to learn, and how to teach, are becoming increasingly important as graduate competencies for all post-secondary students. Through this paper I explore links between metacognition, self-directed learning and lifelong learning. I then discuss strategies to operationalise proactive instruction of metacognition along with my own experiences from introducing metacognition as a learning outcome in a core second year chemical engineering course.

\section{LITERATURE REVIEW}

Metacognition and lifelong learning are clearly linked [5]. Metacognition can be viewed as "knowledge and cognition about cognitive phenomena" [6] or "knowledge of one's knowledge, processes, and cognitive and affective states; and the ability to consciously and deliberately monitor and regulate one's knowledge, processes, and cognitive and affective states" [7]. This second definition more clearly distinguishes knowledge of cognition and regulation of cognition [8,9]. Lifelong learning is "an ability to identify and to address their own educational needs in a changing world in ways sufficient to maintain their competence and to allow them to contribute to the advancement of knowledge [10].

Self-directed learners can "assess the demands of the task, evaluate their own knowledge and skills, plan their approach, monitor their progress, and adjust their strategies as needed" [11]. Self directed learners have a sense of personal agency and develop internalised intrinsic motivation (e.g. mastery) rather than respond to extrinsic goals (e.g. grades or failure). Key to adopting greater intrinsic motivation is developing sences of competence and relatedness, and more importantly, feeling learning autonomy in terms of choice and control [1]. Further self-directed students experience themselves as being central to the learning process rather than perceiving learning as being a process that is done for, or to, them [3]. 
While there are differences at some levels between metacognition, lifelong and self-directed learning these three concepts are clearly related. For example, establishing intrinsic vs extrinsic motivation for learning while at university will presumably set the foundation for lifelong learning. Promoting metacognition should in turn support this intrinsic motivation. Conversely, limited metacognition can promote overconfidence in learning. For example, Toftness et. al report that weaker students may overestimate their learning from lectures, and that this disconnect can grow for very smooth or fluent lectures (e.g. glossy PowerPoint lectures) that make knowledge appear easier to learn than it actually is [12].

Metacognition is not only central to learning, it also underlies critical thinking and hence judgement and decision making [13]. In engineering, knowledge insecurity can inhibit probing more deeply while overconfidence can cause poor decisions, either of which can lead to tragic mistakes. For example, a study of health care providers notes that the subjective feeling of ease with which judgements are made, a biproduct of metacognition, is associated with the certainly of being correct [13].

\section{TEACHING METACOGNITION}

Strategies to operationalise proactive instruction of metacognition are often related to active learning, experiential learning, problem-based learning, and project-based learning. These instructional approaches all typically include elements of ambiguity and student autonomy. In contrast, the certainty associated with content-delivery based instruction offers fewer opportunities to encourage metacognition. Balancing ambiguity, autonomy and motivation can be tricky and require careful consideration in the use of appropriate scaffolding. Too rigid a problem definition will not require students to learn autonomously, and thus restrict any opportunity for students to become aware of their learning. Too much ambiguity may create too large a learning challenge and cause students to lose motivation and give up. Overall development of self-directed and lifelong learners is a multifaceted and complex process that involves creation of appropriate learning experiences and environments so as to integrate learner identity, beliefs about learning, and motivation [1].

Metacognition can provide a conceptual foundation to support lifelong and self-directed learning. For students to learn to practice metacognition they need to first be able to conceptualise it and develop a vocabulary to discuss it. Having students self-assess using inventories can provide these ingredients and support in-class discussion. For example, the 52-statement Metacognitive Awareness Inventory characterises metacognition in terms of eight factors, three related to knowledge about cognition (declarative knowledge, procedural knowledge and conditional knowledge) and five related regulation of cognition (planning, information management strategies, comprehension monitoring, debugging strategies, and evaluation) [14]. While the validity of this inventory to map well onto these factors has been criticized [15], it certainly offers a good starting point for raising awareness so as to engage students in discussion.

Vos proposed "design rules" for active learning in engineering so as to encourage metacognition. His rules include [16]:

- Encouraging students to plan and choose the best way to approach a task;

- Avoid giving students cookbook labs and instead encourage students to propose their own approach;

- Have students evaluate and discuss their approach to problems;

- Encourage students to cooperate in execution but require that they report individually on what they did and learnt.

Tanner created an excellent resource to support the explicit instruction of metacognition based upon the "planning, monitoring and evaluating" framework [17]. An extensive list of questions to promote metacognition was created for different stages of courses (e.g. lectures, assignments test etc.), a few examples of which are:

\section{Planning}

- "What questions do I already have about this topic and I want to find out more about?

- How does success in this course relate to my career goals?

\section{Monitoring}

- What insights am I having while I experience this class session?

- What did I hear today that is in conflict with my prior understanding?

\section{Evaluating}

- What advice would I give to a friend about how to learn the most in this course"?

Sample prompts are also provided for integrating metacognition into active learning in the classroom, assignments and preparation for tests.

Guided reflection is another important instructional approach that can promote metacognition as described in a companion paper [18]. Course conditions required for effective reflection included cognitive autonomy, 
effective feedback and work of appropriate challenge [19].

Intentional teaching of metacognition requires instructors to be aware of their own learning processes. While most instructors have chosen careers in academia because they are inherently lifelong learners, they may still be unaware of their own learning processes. For example, engineering instructors may teach about complex and multifaceted design approaches without applying these same design approaches to their own instruction. As Stubley notes in a companion paper, instructors may encourage student to design based upon understanding the underlying fundamentals, yet not design their own teaching based on a fundamental understanding of learning [20].

The Metacognitive Awareness Inventory for Teachers provides a useful tool for instructors to reflect on their own development [21]. This in 24-staement inventory characterises an instructor's knowledge about their own teaching (declarative knowledge, procedural knowledge and conditional knowledge) and how they regulation their thinking about teaching (planning, monitoring, debugging and evaluating). Tanner [17] also created a wonderful inventory of reflection questions for instructors to think about and develop greater awareness of their teaching based on the planning, monitoring and evaluating framework:

- What do I think that students already know about this topic?

- How does success in this course relate to my students' career goals?

- What do I want students to still be able to do 5 years later?

- How is my approach to teaching this course different from last time I taught it? Why?

- What evidence do I have that students in my course learned what I think they learned?

\section{APPLICATION IN A CORE COURSE}

This year I wove concepts related to metacognition into CHE230, a core second year chemical engineering course on environmental chemistry. This course has an iterative instructional design with many elements of cooperative learning [22]. Central to the course is a teambased design project wherein students create their consulting engineering companies so as to bid against each other on a call for proposals from Wallberg International, a fictitious multinational company. This part of the course is co-interacted by practicing environmental consultants along with instructors from the
Engineering Communication Program, who serve as the clients [23]. This year's projects featured air quality in Sarnia's refinery valley, contaminated land around a gold mine in Northern Ontario, and Goggle's intention to convert of a former industrial site in Toronto's portlands into a leading edge sustainable community.

Instruction of CHE230 covers many of the CEAB graduate attributes. However, prior to this year I did not include intentional instruction of metacognition and lifelong learning. I felt that introducing the students to metacognition would be feasible, given that the course's design allows students cognitive freedom in tackling a complex, ill-defined and messy problem requiring novel learning. Students are required to address new material that is introduced with limited scaffolding so as to help them to develop their ability to independently identify and address gaps in their knowledge.

The course already had material available explaining to students the reasons for the course's iterative and cooperative instructional design. In prior years this was only briefly mentioned in the introductory lecture. This year I introduced students to concepts related to learning in the lectures during the first weeks of the course. Metacognition was also discussed before the course started with the teaching assistants and the course coinstructors. Here the environmental consultant coinstructors provided some excellent examples of how essential "knowledge of one's knowledge" was to them in selecting which jobs to bid on.

In lecture, I introduced students to a constructivist approach to learning. Here I used a jigsaw puzzle analogy to constructing knowledge, emphasising the need for them to quickly connect pieces of knowledge they were "handed" in class to their existing knowledge base. I warned the students that the "pieces of knowledge" they were handed might look somewhat different to each of them, based on their individual perceptions, as might be the connections they made. I urged them to work with each other as it would allow them to test their understanding and build richer "pictures" together.

In another lecture, the students were asked to play a game I call "see the world as a chemical engineer". Here students were asked to identify something that had seen in the last few days (e.g. wind in the trees, water in a sink) and relate it to as many chemical engineering concepts as they could. They were then asked to describe what they had seen to a partner from a chemical engineering perspective. The goals of this simple exercise were to help students to:

- See how theory can provide a foundation to understanding observation, 
- Contextualise the knowledge they were acquiring

- $\quad$ Build identity as engineers

Underlying this exercise was the idea of using reflection to link theory and observation. The course also already included two reflections on team skills, and these were left unchanged [24,25].

After the end of the course, once exams were over, I sent the students an email encouraging them to do a postcourse reflection on what they had learnt. I provided questions to guide this reflection and give them a way to share their thoughts anonymously through the course learning management system. Completion of this reflection was entirely optional and worth no grades. The guiding questions provided included:

- Where might you someday apply technical concepts from CHE230 beyond this course?

- What did you learn about how you learn through this course?

- How may you change your approach to learning in future courses?

- What can you do during your undergraduate studies will position you to continue to learn throughout your career?

Very few students shared their thoughts through the course website, although many more opened the announcement about the reflection and may have done it on their own. The comments from the few student replies were encouraging. Some students noted that:

- Iteration helped their learning and made studying for exams less stressful;

- $\quad$ Specifying learning outcomes and linking these to applications helped motivate learning;

- Formative feedback from the practicing environmental consultants provided authenticity and credibility, making the learning more real.

- Reflection was a valuable part of learning

The course was designed so that students typically see concepts up to six times (course text, lecture, worked examples, tutorial, quiz, midterm/final exam) with only the last one being high stakes. Hence it was gratifying that the students noted and saw benefits in this iterative instructional design. Learning outcomes were also specified through the course text as well as in lectures, and the linking of outcomes to graduate attributes and summative assessment was discussed with the students.

\section{SUMMARY}

Lifelong learning is becoming an increasingly important competency for career success as an engineer. Metacognition, lifelong and self-directed learning are clearly related and instruction of metacognition can provide a conceptual foundation for the other two.

Instruction of metacognition involves creation of appropriate learning experiences and environments that support open ended learning so as to balance autonomy, ambiguity, and student motivation. Numerous instructional resources such as awareness inventories already exist that can support creation of instructional modules and integration of related learning throughout a course. The preliminary incorporation of metacognition learning into a core course provided promising results, and a more effective instructional strategy will be created for next year. Overall, opportunities exist to integrate metacognition into undergraduate engineering that should yield major benefits to students.

\section{Acknowledgements}

The present study was prompted from and benefited from numerous discussions with the 2017 3M National Teaching Fellows cohort, Gordon Stubley and Alan Steele in particular. The support of 3M Canada and the Society for Teaching and Learning in Higher Education (STLHE) is gratefully acknowledged.

\section{References}

[1] Stolk J, R. Martello, K. Koehler, K.C. Chen and R. Herter "A Troubled Attempt to Quantitatively Measure Engineering Students' Lifelong Learning Development Over Two Years of College" in Frontiers in Education Conference IEEE, Madrid Spain, 2014

[2] Kamp A. Engineering Education in a Rapidly Changing World Rethinking the Vision for Higher Engineering Education TU Delft, Second Revised Edition, 2016

[3] Ulseth R., "Development of PBL Students as SelfDirected Learners" in proc. Annual Conference and Exposition of the American Society for Engineering Education, 2016

[4] Harrison A., Skills Competencies and Credentials Higher Education Quality Council of Ontario, 2017

[5] Marra, R.M., S.M. Kim, C. Plumb, D.J. Hacker, S. Bossaller "Beyond the Technical: Developing Life Long Learning and Metacognition for the Engineering Workplace" in Proc. Annual Conference and Exposition of the American Society for Engineering Education, 2017

[6] Flavell, J.H. "Metacognition and cognitive monitoring: A new area of cognitive developmental inquiry” American Psychologist, 34, pp 906-911, 1979 
[7] Hacker, D.J. J. Dunlosky and A.C. Graesser Metacognition in Educational Theory and Practice Taylor and Francis New York, 1998

[8] Sperling R.A, B.C. Howard, R. Staley and N. DuBois "Metacognition and Self-Regulated Learning Constructs" Education Research and Evaluation vol. 10 no. 2 1117-139, 2004

[9] Zimmerman BJ. "Becoming a self-regulated learner: Which are the key subprocesses?" Contemp. Educ Psychol. 11:307-13, 1986

[10] Canadian Engineering Accreditation Board 2017 Accreditation Criteria and Procedures https://engineerscanada.ca/sites/default/files/accreditat ion-criteria-procedures-2017.pdf

[11] Ambrose, S. A., M. W. Bridges, M. DiPietro, M. C. Lovett, M. K. Norman How learning works: Seven Research-Based Principles for Smart Teaching, John Wiley \& Sons, 2010

[12] Toftness A.R. S.K. Carpenter, J. Geller, S. Lauber, M. Johnson P. I. Armstrong "Instructor fluency leads to higher confidence in learning, but not better learning" Metacognition and Learning, vol.13 pp 1-14, 2018.

[13] Medina M.S. A. N. Castleberry and A. M. Persky "Strategies for Improving Learner Metacognition in Health Professional Education" Am J Pharm Educ., vol 81 no. 4 Article 78, 2017

[14] Schraw G and Dennison R S "Assessing Metacognitive Awareness" Contemp Educ Psychol, 19 pp 460-475 1994.

[15] Harrison G.H. and L.M. Vallin "Evaluating the metacognitive awareness inventory using empirical factor-structure evidence" Metacognition and Learning vol.13 pp15-38, 2018.

[16] Vos, H. and E De Graaff' Developing metacognition: a basis for active learning" Euro J. of Eng Educ. Vol 29 no 4 pp543-548, 2004

[17] Tanner K.D. "Promoting Student Metacognition" Life Sciences Education vol.11 pp113-120, 2012.
[18] Steele, A.L. "Developing Student Meta-Cognition In A Design Course" in Proc 2018 Canadian Engineering Education Association Conference, Vancouver, 2018

[19] Burger, J., P. Cote, N. Dhanushkodi, J. D. Stolk, and Y. V. Zastavker "Transforming challenges into reflections: Enabling metacognitive development" in Frontiers in Education Conference IEEE, Madrid Spain, 2014

[20] Stubley G. “Thinking About Learning - Inferences From How We Support Curriculum Design" in Proc 2018 Canadian Engineering Education Association Conference, Vancouver, 2018

[21] Balcikanli C. "Metacognitive Awareness Inventory for Teachers" Electronic Journal of Research in Educational Psychology, vol.9 no. 3 pp1309-1332, 2011.

[22] Evans G.J., M. McGuire, D, Tihayni "Using Environmental Consulting as a Team Design Project: Role Play to reality" in Proc. 2010 Canadian Engineering Education Conference, Kingston, 2010

[23] Evans G.J., P. Sheridan, D. Reeve, M. McGuire, K. Minnella, E. Oliva-Fisher, L. Wilkinson, and T. McAlary. "Incorporating Team Effectiveness as a Learning Objective in the Design Project within a Technical Core" in Proc 2013 Canadian Engineering Education Association Conference, Montréal, Canada, 2013.

[24] Sheridan, P.K. P.M. To A., G. Evans and D. Reeve, "An On-line Team Effectiveness Learning System". in Proc 2014 Canadian Engineering Education Association Conference, Calgary, Canada, 2014.

[25] Sheridan P.K., A. Malone, D. Reeve, and G. Evans, "Seeing into your Teams, An Instructor Interface to Support Team Learning" in Proc. 2015 Canadian Engineering Education Association Conference, Hamilton, Canada, 2015. 